LETTER

\title{
Prevalence of Ehrlichia muris in Wisconsin Deer Ticks Collected During the Mid 1990s
}

\author{
Sam R. Telford III*, Heidi K. Goethert and Jenny A. Cunningham \\ Tufts University, Cummings School of Veterinary Medicine, 200 Westboro Road, North Grafton, MA 01536, USA
}

\begin{abstract}
Human ehrlichiosis is due to infection by tick transmitted bacteria of the genus Ehrlichia. Based on a hypothesis for the biogeography of deer tick transmitted infections, we undertook a focused search for the Eurasian $E$. muris in North American deer ticks. The search was stimulated by anecdotal reports of E. muris-like infection in human ehrlichiosis patients from Wisconsin. We analyzed archived adult deer ticks collected in northern Wisconsin during the 1990s by specific polymerase chain reaction for evidence of infection, and sequenced amplification products to identify E. muris. About $1 \%$ of 760 adult deer ticks collected from Spooner, Wisconsin in the 1990s contained E. muris DNA. We conclude that E. muris was present in North American deer ticks a decade ago and is likely to infect this human biting vector elsewhere in the U.S. Biogeographic theory and molecular phylogenetic methods can facilitate a targeted search for potential zoonoses.
\end{abstract}

Keywords: Ehrlichiosis, deer ticks, Wisconsin, Ehrlichia muris, Ixodes dammini, PCR.

\section{INTRODUCTION}

Human ehrlichiosis, a zoonosis with a global distribution, is an acute disease of varying severity comprising fever, headache, malaise and myalgia, with nonspecific physical findings; laboratory findings generally include leukopenia, thrombocytopenia, and elevated liver function tests. The obligately intracellular alpha-proteobacterial genus Ehrlichia (Rickettsiales: Anaplasmataceae) comprises 5 recognized species, all tick-transmitted, with 3 of the 5 causing human ehrlichiosis (E. canis, E. chaffeensis, and E. ewingii). In addition, numerous candidatus entities have been reported ("E. walkerii", "E. shimanensis", "Ixodes ovatus ehrlichia", "Panola Mountain ehrlichia" and others), all from hard ticks and mainly characterized by PCR sequencing [1]. Their capacity to infect humans remains to be described. The agent of the important veterinary disease heartwater (E. ruminantium) is not known to be zoonotic. Ehrlichia muris was first described from the vole Eothenomys kageus as well as from muroid rodents in Japan [2, 3] and has not been associated with human infection there. E. muris has also been identified from Ixodes persulcatus ticks across Russia and from $I$. ricinus in Slovakia [4-7], suggesting the possibility that it is a member of the Holarctic microbial guild maintained by rodent-feeding ticks in the I. persulcatus species complex [8, 9]. These ticks are human biters and globally are the main vectors of Lyme disease. Recently, anecdotal information has been presented (ProMed Mail, 15 May 2010, archive \#20100515.1593) on the identification of E. muris-like DNA from the blood of American patients who had presented with

*Address correspondence to this author at the Tufts University, Cummings School of Veterinary Medicine, 200 Westboro Road, North Grafton, MA 01536, USA; Tel: 508-887-4236; Fax 508-839-7911;

E-mail sam.telford@tufts.edu signs and symptoms compatible with human anaplasmosis (human granulocytic ehrlichiosis due to Anaplasma phagocytophilum). Similar DNA was said to have been detected in deer ticks (I. dammini, the main American vector of Lyme disease; also known as I. scapularis) as well but no details have been formally reported. The case-patients were residents of Wisconsin and Minnesota, an area we have previously suggested $[8,10,11]$ was a glacial refugium for the deer tick microbial guild (Borrelia burgdorferi, Babesia microti, A. phagocytophilum, tick borne encephalitis group viruses). Because of our hypothesis that E. muris is indeed a member of the deer tick guild, we reasoned that it might be easily found in ticks from longstanding sites of transmission. Accordingly, we analyzed archived samples of adult deer ticks we collected from vegetation during October of 19921997 in Spooner, Wisconsin for evidence of infection by $E$. muris.

Adult deer ticks (males and females) were collected by sweeping vegetation in a study site in Spooner, Wisconsin during October 1992-1997, and stored desiccated at room temperature. The ticks were pooled and homogenized in groups of 6 and their DNA extracted using alkaline lysis. To determine whether ticks contained E. muris DNA, we used a nested PCR targeting the citrate synthase gene of E. muris. The primers used were EmCS638F/EmCS1349R [12] for the outer reaction, and EmCS innerF/ EmCS innerR (Table 1). Samples testing positive for E. muris were confirmed by amplifying Groesl and 16S rRNA gene targets; we considered only those samples that were confirmed by at least one other target to be positive. We compared the prevalence of $E$. muris infection with that of A. phagocytophilum by PCR for the latter agent using the nested primer set BacA/1448r and Ge9f/Ge10r [13]. Amplicons were excised from agarose gels, purified, and commercially sequenced. 
Table 1. Primers used for PCR to Detect and Confirm the Presence of E. muris DNA

\begin{tabular}{|c|c|c|c|c|}
\hline Name & Sequence & Target & Size & Source \\
\hline EmCS638F & TACAGATTTCTCAAGAATATACA & citrate synthase & 712 & {$[12]$} \\
\hline EmCS1349R & AATGCAATGTTTTCTAATTCTAC & & & \\
\hline EmCS innerF & TGGCATGTTTTTCTGCCT TA & citrate synthase & 641 & this study \\
\hline EmCS innerR & TGACCAAAACCCATTAATCTTG & & & this study \\
\hline MUR-Groel-F & GGATCCATTGGCTCTTGCTA & Groel & 970 & this study \\
\hline MUR-Groel-R & CCACCAACCTTTAAGACAGCA & & & this study \\
\hline MUR-Groel-INF & AAGGGATTCAAAGAATTGGATG & & 617 & this study \\
\hline MUR-Groel-INR & CCACCAACCTTTAAGACAGCA & & & this study \\
\hline $\mathrm{BacA}$ & AGAGTTTGATCCTGGCTCAG & $16 \mathrm{~S}$ & 596 & {$[13]$} \\
\hline Mur1R & СGCTATCCTCTTTCGACCTCT & & & this study \\
\hline
\end{tabular}

Of 760 ticks, 7 (maximum likelihood estimate of prevalence for pooled samples $0.94 \%$ [ $95 \%$ confidence interval, 0.42-1.9]) tested positive for E. muris-specific DNA. Phylogenetic analysis (Fig. 1) demonstrates that the sequences we detected (GenBank submissions HQ660491-HQ660497) in the Spooner ticks clustered with those from Eurasian $E$. muris, and we conservatively interpret the small degree of nucleotide difference as due to geographic variation as opposed to evidence for a "new" agent. We analyzed 670 of the 760 ticks for A. phagocytophilum DNA and 3 were considered positive (MLE $0.45 \%$ [0.12, 1.2]). It is likely that the mode of storage (desiccation) diminished sensitivity of the assays because we previously reported a prevalence of about $4 \%$ (by microscopy) for A. phagocytophilum from the
Spooner site [14]; thus, the prevalence of E. muris is likely greater.

We conclude that E. muris was present in Wisconsin more than a decade before the recent anecdotal report of atypical human ehrlichiosis cases, and that it was as prevalent in host-seeking adult deer ticks there as was A. phagocytophilum. The Spooner area was where erythema migrans was first noted in North America [15], where the first Midwestern cases of B. microti babesiosis occurred [16] and where the first cases of HGE were detected [13]. Our field sampling in Spooner during the 1990s reflected an interest in the comparative ecology of B. microti, A. phagocytophilum and deer tick virus with respect to the New England terminal
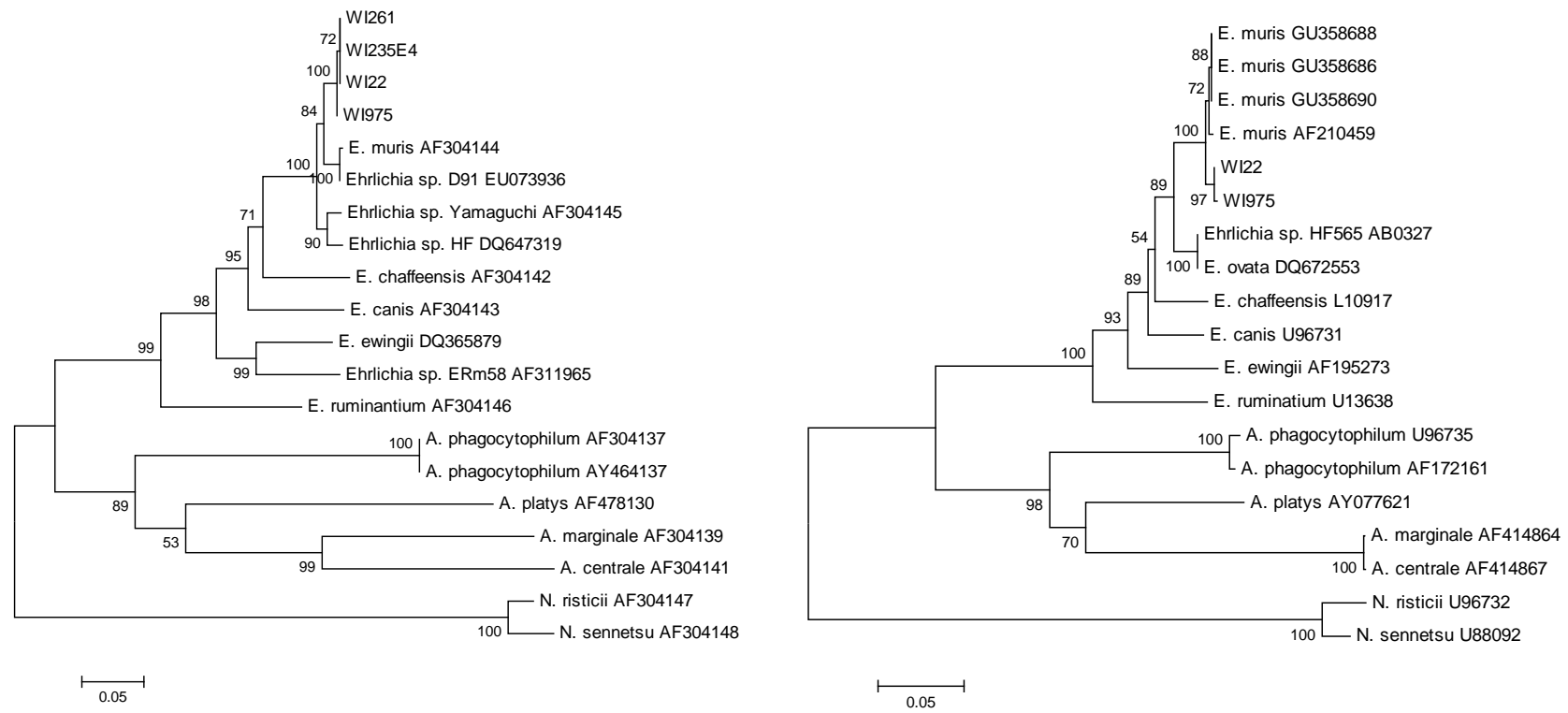

Fig. (1). Phylogenetic analysis of Ehrlichia sp. DNA amplified from archived adult deer ticks collected in Spooner, Wisconsin during 19921997. DNA sequences of other Ehrlichia spp. were downloaded from NCBI Genbank, aligned using ClustalW, and then adjusted by eye using GeneDoc. MEGA was used to generate neighbor-joining trees for citrate synthase (left panel) and groesl (right panel) sequences using the Kimura 2-parameter model. 500 bootstrap replicates were done to assess the stability of the resulting branch nodes. 
moraine sites of longstanding transmission. The detection of E. muris in ticks from Spooner is consistent with (but not proof of) our hypothesis of a glacial refuge where the deer tick microbial guild has been present since its likely introduction via Beringia. It may be that $E$. muris will be found in the U.S. wherever deer ticks are known to be infected by a majority of the guild members. Some human ehrlichiosis cases may eventually be demonstrated to comprise infection by E. muris.

\section{ACKNOWLEDGEMENTS}

Field studies for this work were supported by NIH AI 19693 and AI 39002. We are currently supported by NIH AI 064218.

\section{REFERENCES}

[1] Brouqui P, Matsumoto K. Bacteriology and phylogeny of Anaplasmataceae. Pp 179-198 in Rickettsial Diseases, eds Raoult D, Parola P. Informa Healthcare, NY, 2008.

[2] Kawahara M, Suto C, Rikihisa Y, Yamamoto S, Tsuboi Y. Characterization of ehrlichial organisms isolated from a wild mouse. J Clin Microbiol 1993; 31:89-96

[3] Wen B, Rikihisa Y, Mott J, Fuerst PA, Kawahara M, Suto C. Ehrlichia muris sp. nov., identified on the basis of $16 \mathrm{~S}$ rRNA base sequences and serological, morphological, and biological characteristics. Int J Syst Bacteriol 1995; 45:250-4

[4] Ravyn MD, Korenberg EI, Oeding JA, Kovalevskii YV, Johnson RC. Monocytic Ehrlichia in Ixodes persulcatus ticks from Perm, Russia. Lancet 1999; 353: 722-3.

[5] Alekseev AN, Dubinina HV, Van De Pol I, Schouls LM. Identification of Ehrlichia spp. and Borrelia burgdorferi in Ixodes ticks in the Baltic regions of Russia. J Clin Microbiol 2001; 39:2237-42
[6] Shpynov S., Fournier PE, Rudakov N, Tarasevich I, Raoult D. Detection of members of the genera Rickettsia, Anaplasma, and Ehrlichia in ticks collected in the Asiatic part of Russia. Ann N Y Acad Sci 2006; 1078:378-83

[7] Spitalská E, Boldis V, Kostanová Z, Kocianová E, Stefanidesová $\mathrm{K}$. Incidence of various tick-borne microorganisms in rodents and ticks of central Slovakia. Acta Virol 2008; 52:175-9

[8] Telford SR III, Gorenflot A, Brasseur P, Spielman A. Babesial infections in man and wildlife. Pp 1-47 in Parasitic Protozoa, $2^{\text {nd }}$ edition, Volume 5, ed. Kreier JP. Academic Press, San Diego, 1993.

[9] Telford SR III, Goethert HK. Emerging and emergent tickborne infections. Pp 344-376 in Ticks: Biology, Disease, and Control. Eds. Chappell LH, Bowman AS, Nuttall PA. Cambridge University Press, 2008.

[10] Telford SR III, Dawson JE, Katavolos P, Warner CK, Kolbert CP, Persing DH. . Perpetuation of the agent of human granulocytic ehrlichiosis in a deer tick-rodent cycle. Proc Nat Acad Sci USA 1996. 93:6209-14

[11] Telford SR III, Dawson JE, Halupka KC. Emergence of tick borne diseases. Sci Med 1997; 4:24-33

[12] Tamamoto C, Seino N, Suzuki M, Kaji K, Takahashi H, Inokuma H. Detection of Ehrlichia muris DNA from sika deer (Cervus nippon yesoensis) in Hokkaido, Japan. Vet Parasitology 2007; 150:370-3

[13] Chen SM, Dumler JS, Bakken JS, Walker DH. Identification of a granulocytotropic Ehrlichia species as the etiologic agent of human disease. J Clin Microbiol 1994; 32:589-95

[14] Ebel GD, Foppa I, Spielman A, Telford SR III. A focus of deer tick virus transmission in the north-central United States. Emerg Infect Dis 1999; 5:570-4

[15] Scrimenti R. Erythema chronicum migrans. Arch Dermatol 1970; 102:104-5.

[16] Steketee RW, Eckman MR, Burgess EC, Kuritsky JN, Dickerson J, Schell WL, Godsey MS, Davis JP. Babesiosis in Wisconsin: a new focus of disease transmission. JAMA 1985; 253:2675-8. 